\title{
Evaluation of faculty inter-variability OSCE grade scoring on overall student performance in a laboratory course
}

\author{
Salome Bwayo Weaver (D), Monika Daftary (D), La'Marcus Wingate (D), Malaika Turner (D) \\ Howard University College of Pharmacy, Washington DC, United States
}

Keywords
Faculty
Inter-variability
Objective Structured Clinical Examination (OSCE)
Performance

\section{Correspondence}

Salome Bwayo Weaver

Howard University College of Pharmacy

23004 th St NW

Washington DC 20059

United States

skbwayo@howard.edu

\begin{abstract}
Introduction: Objective structured clinical examinations (OSCEs) are considered the gold standard for evaluating pharmacy students' clinical skills due to their reliability and validity. Aim: The purpose of this study was to determine whether faculty inter-variability in OSCE grading had a significant impact on a student's overall performance. Methods: A retrospective analysis was conducted using data from two cohorts of third-year pharmacy students. Descriptive statistics, simple linear regression, and multivariate linear regression analyses were conducted. Results: There were 120 students that participated in the OSCE with a mean score of $66.7 \%$. Higher scores in the Integrated Therapeutics (IT) 2 lecture series and the IT 2 lab course corresponded to better OSCE scores. Out of 17 evaluators, six were found to rate students significantly lower and one was found to rate students significantly higher in comparison to a reference evaluator who evaluated students closest to the overall mean. Conclusion: It is likely that standardised grading, and possibly additional training, may be needed to ensure a fair and appropriate evaluation of OSCE performance.
\end{abstract}

\section{Introduction}

One of the most widely used tools to assess clinical or practical competency is the objective structured clinical examination (OSCE) (Vanka et al., 2018). The OSCE is now a principal method for assessment across various health professions (Sola et al., 2017, Shahzad et al., 2017, Duanmu et al., 2019) and is considered to be the 'gold standard' in evaluating pharmacy students' clinical skills due its reliability and validity (Shirwakar, 2015). The use of OSCE's in pharmacy can also be used as a method of evaluating readiness to enter practice and continuing competency of its pharmacist members (Kirton \& Kravitz, 2011). A study by Sturpe described the best OSCE practices in the United States among different Doctor of Pharmacy (Pharm. D.) programmes (Sturpe, 2010). The best practices outlined in the study consisted of examining and validating key items such as OSCE stations and examination content developed by various faculty groups (Sturpe, 2010).
Though there are issues noted in the literature with assessing student performance in relation to the OSCE, advantages are noted in the provision of this type of competency-based assessment over more traditional paper-based assessments (Barman, 2005; Corbo et al., 2006; Salinitri et al., 2012). However, Barman and colleagues provided a critique on the OSCE examination based on reliability, validity, objectivity and feasibility (Barman, 2005). Additionally, a study by Sobh evaluated the application of a systemic approach to reviewing psychometric properties of a cumulative OSCE (Sobh et al., 2017). This approach reviewed predictive and concurrent validity, internal and content validity, inter-rater reliability and internal consistency. (Sobh et al., 2017). The validity, objectivity, and reliability of any assessment, but especially the OSCE, is important.

The Howard University College of Pharmacy has utilised OSCEs as an assessment activity since 2009. However, over the years, concern was raised in student evaluations and feedback that faculty evaluations may 
not have consistently embodied the tenets of being reliable, valid, and objective. There are various factors that can influence the OSCE's objectivity, and this may include the standardisation of tasks, order of stations, time constraints, examiner and standardised patient (SP) fatigue from repetition (Barman, 2005). It is crucial to the implementation of OSCEs to ensure that both the standardised patients and evaluators are adequately trained (Reid et al., 2016; Mafinejad et al., 2017). The Howard University College of Pharmacy utilised the faculty to grade student OSCEs. However, due to time limitations, they were not often consistently trained prior to the implementation of each case. Faculty workload had also impacted the ability of more than two faculty to develop and validate an OSCE. Therefore, the objective of the study was to assess if faculty intervariability scoring on the OSCE had a significant impact on students' overall performance.

\section{Methods}

The Howard University College of Pharmacy offers a four-year program for students to obtain the Pharm. D. degree. The didactic portion is $70 \%$ of the program and completed within the first three years, while $30 \%$ is experiential and completed over the summers and during the fourth year of pharmacy school. The integrated therapeutics laboratory course series is offered for four consecutive semesters to the second and third-year pharmacy students. The Integrated Therapeutics (IT) laboratory 2 course was conducted in the autumn of the third year and focused on the therapeutic areas of infectious disease, haematology and oncology. During the course, the student was expected to acquire the knowledge and skills required to appropriately recommend and dispense therapeutic options, including prescriptions, over the counter, complementary and alternative medicines, medical devices and other health care products.

Three faculties members from the Howard University College of Pharmacy went to the University of Toronto in June 2009 to receive training in the development and implementation of OSCEs in the IT laboratory courses. A bank of eight cases was developed and vetted prior to implementation in autumn 2009. Over the course of the past ten years, students were exposed to various cases involving patient/pharmacist, patient/physician as well as patient/nursing interactions. New cases have been developed over the years to reflect current and contemporary practice based on the most recent set of evidence-based guidelines in 2021. The objective of the OSCEs was to assess skills related to problem-solving, communication, interpersonal relations and critical thinking, and they were completed as low-stakes examinations. Some of the cases included topics such as hypertension, hyperlipidemia, heart failure, anticoagulation, breast cancer, prostate cancer, tuberculosis, human immunodeficiency virus, febrile neutropenia, pain management, sickle cell disease, community-acquired pneumonia, traveller's diarrhoea and osteoarthritis. The cases were created and developed by the course coordinator, post-graduate trainees and the faculty who taught the content using a standardised rubric created by the College of Medicine. The cases were then disseminated to the standardised patient (SP) educator four to six weeks ahead of time to aid with recruitment of the SP based on specific demographics. The SP educator set up a time to meet with the SPs and trained them to role play as a patient/physician/nurse based on the criteria set by the faculty.

The faculty utilised a grading rubric to evaluate the students' ability to identify the main therapeutic problem such as drug allergy/intolerance, adverse drug reaction, medication reconciliation, drug/drug interaction, drug/disease interaction, uncontrolled condition, wrong dose, supratherapeutic or subtherapeutic doses, duplication of therapy, and prior authorisation or rejection claims. This portion of the grade was worth 40 points. The second portion of the grade, worth 10 points, consisted of five questions that were two points each based on a global assessment scale. The global assessment scale evaluated verbal and non-verbal expressions, response to patient's feelings and needs, the degree of focus, logic and coherence utilising a Likert scale measuring from one to five, with five denoting the highest score. This was done once in the middle of the semester and again at the end. The global assessment scale had been previously graded by the faculty; however, based on students' feedback, changes were made in autumn 2019 to allow the SP to grade the global assessment scale.

\section{Study design}

A retrospective cross-sectional study was conducted using data from two classes of students enrolled in the Howard University College of Pharmacy IT laboratory 2 course as a part of their third professional year in 2016 and 2017. Students were excluded from the study if they had withdrawn from the course or were dismissed from the pharmacy program during the study period. Data were derived from the computerised clinical skills software called the B-Line system at the Howard University College of Medicine. The study was approved by the Howard University Institutional Review Board (IRB) in January 2020. 


\section{Study variables}

The independent variable in the study was the intervariability between individual faculty members evaluating the students on the OSCE. The dependent variable was the student's score on the OSCE. There were several covariates that could be assessed prior to admission into the Pharm. D. programme, including age, gender, ethnicity/race, both overall and science-related grade point average (GPA) at admission, Pharmacy College Admission Test (PCAT) score, and score on a 40-question mathematics examination administered at admission. In addition, covariates were included to estimate the student's academic proficiency based upon their performance in pharmacy school, including the GPA during the first semester in pharmacy school, the score on the California Critical Thinking Skills Test (CCTST), the third-year Pharmacy Curriculum Outcomes Assessment (PCOA) test score, the GPA in the lecturebased IT courses associated with the laboratory course, and the GPA in the IT laboratory 2 course.

\section{Statistical analyses}

Descriptive statistics were conducted to describe students' baseline characteristics. Means and standard deviations were used to describe continuous variables, while frequencies and proportions were utilised in characterising categorical variables. The Pearson's correlation coefficient was used to determine if there was a linear association between the covariates and the student score on the OSCE. A multivariate linear regression model was developed to determine if the individual assigned to evaluate the students had a significant influence on the student's overall performance on the OSCE after adjusting for variables that were demonstrated to have a significant association with the OSCE in the Pearson's Correlation. SPSS version 23 was used for all data analysis. The evaluator who graded students closest to the mean of all of the evaluators was chosen to be the reference evaluator. The fit of the R2 model was assessed via the R2 statistic. A two-sided test was used for all inferential statistics, and $p$-values less than 0.05 were considered to be statistically significant.

\section{Results}

As seen in Table I, 120 students participated in the OSCE as third-year pharmacy students in 2016 and 2017. The majority of the students (72.5\%) were black, and slightly over half (56.7\%) were female, with an average age of $24.6+4.7$ years at admission. The cumulative undergraduate GPA was $3.20+0.29$, the cumulative undergraduate science GPA was $3.09+$ 0.35 , and the mean GPA during the first semester of pharmacy school was $3.28+0.49$. The mean GPA in the three lecture-based courses that coincided with OSCE labs was $2.74+0.48$, and the mean GPA in the IT laboratory 2 course was $3.18+0.50$. The mean score on the first and second OSCE was $66.7+13.3$ and $73.0+10.9$, respectively.

Table I: Baseline characteristics for students taking OSCEs at a College of Pharmacy in 2016 and 2017 $(\mathrm{N}=120)$

\begin{tabular}{|c|c|}
\hline Characteristics & Mean+SD \\
\hline \multicolumn{2}{|l|}{ Admissions based } \\
\hline \multicolumn{2}{|l|}{ Race } \\
\hline Black, number (\%) & $87(72.5)$ \\
\hline Asian, number (\%) & $22(18.3)$ \\
\hline Other, number (\%) & $11(9.2)$ \\
\hline Female, number (\%) & $68(56.7)$ \\
\hline Age at admission & $24.6 \pm 4.7$ \\
\hline Cumulative undergraduate GPA & $3.20 \pm 0.29$ \\
\hline Cumulative undergraduate science GPA & $3.09 \pm 0.35$ \\
\hline Composite PCAT & $62.2 \pm 14.2$ \\
\hline Math Interview Score & $31.6 \pm 4.6$ \\
\hline \multicolumn{2}{|l|}{ Pharmacy school-based } \\
\hline First Semester GPA in Pharmacy School & $3.28 \pm 0.49$ \\
\hline Critical Thinking Skills Score Test & $77.3 \pm 8.1$ \\
\hline PCOA Scaled Score (Third year) & $334.4 \pm 37.8$ \\
\hline GPA across IT2A to IT2C & $2.74 \pm 0.48$ \\
\hline IT Lab 2 GPA & $3.18 \pm 0.50$ \\
\hline OSCE \#1 Score & $66.7 \pm 13.3$ \\
\hline
\end{tabular}

Abbreviations: GPA: Grade Point Average; IT: Integrated Therapeutics; OSCE: Objective Structured Clinical Examination; PCAT: Pharmacy College Admission Test; PCOA: Pharmacy Curriculum Outcomes Assessment

The results from the Pearson's Correlation Analysis are depicted in Table II. The GPA in the IT Laboratory 2 course had a correlation coefficient of 0.224 , which represented a significant association with the OSCE grade $(p=0.014)$. In addition, the mean GPA in the lecture-based IT courses administered during the same semester had a significant association with the student's OSCE grade with a correlation coefficient of 0.192 and a $p$-value of 0.037 . None of the other variables measured had a significant correlation with the student's grade on the OSCEs. 
Table II: Correlation of academic factors with students OSCE grades

\begin{tabular}{lcc}
\hline Variable & $\begin{array}{c}\text { Correlation } \\
\text { coefficient }\end{array}$ & $\begin{array}{c}\boldsymbol{p} \text { - } \\
\text { value }\end{array}$ \\
\hline OSCE \#2 & -0.138 & 0.137 \\
IT Lab 2 GPA & 0.243 & $0.008^{*}$ \\
$\begin{array}{l}\text { GPA in IT2A to IT2C lecture- } \\
\text { based courses }\end{array}$ & 0.214 & $0.019^{*}$ \\
$\begin{array}{l}\text { First Semester GPA in } \\
\text { Pharmacy School }\end{array}$ & 0.019 & 0.836 \\
$\begin{array}{l}\text { Cumulative Undergraduate } \\
\text { GPA }\end{array}$ & -0.046 & 0.615 \\
$\begin{array}{l}\text { Cumulative Undergraduate } \\
\text { Science GPA }\end{array}$ & -0.016 & 0.860 \\
$\begin{array}{l}\text { Age } \\
\text { Cumulative PCAT }\end{array}$ & 0.100 & 0.279 \\
$\begin{array}{l}\text { Math Interview Score During } \\
\text { Interviews }\end{array}$ & -0.017 & 0.858 \\
Third-year PCOA Score & 0.110 & 0.232 \\
$\begin{array}{l}\text { California Critical Thinking } \\
\text { Skills Score }\end{array}$ & 0.095 & 0.308 \\
\hline
\end{tabular}

Abbreviations: GPA: Grade Point Average; IT: Integrated Therapeutics; OSCE: Objective Structured Clinical Examination; PCAT: Pharmacy College Admission Test; PCOA: Pharmacy Curriculum Outcomes Assessment *Significant results $(p<0.05)$

The results from the multivariate regression model are shown in Table III. The $\mathrm{R}^{2}$ value of the model was 0.510 . After adjusting for the IT Laboratory 2 grade and mean GPA in IT lecture courses, six evaluators were found to rate students significantly lower, and one was demonstrated to give scores significantly higher in comparison to a reference evaluator who graded students close to the average of all students. When compared to the reference evaluator, one rater graded students as much as 19.5 points lower $(p=0.001)$ than the reference faculty member. In contrast, another evaluator gave students a grade that was 12.3 points higher $(p=0.039)$ than the reference evaluator.

\section{Discussion}

The purpose of this study was to evaluate faculty intervariability OSCE grade scoring overall impact on student performance in a laboratory course. The focus of the study examined consistency between faculty on the grading of an OSCE examination. Variation between graders can have an impact on a student's laboratory course grade, and therefore, could also have an overall impact on their overall performance in the programme. Furthermore, research has found raters of performance assessments, such as OSCE exams, are affected by human judgement and, therefore, susceptible to the evaluation of the rater, be it grading too easy or too hard (Bartman et al., 2013).
Table III: Multivariate linear regression analysis of factors impacting students OSCE grades

\begin{tabular}{|c|c|c|c|c|}
\hline Variable & Beta & $\begin{array}{l}\text { Std. } \\
\text { Error }\end{array}$ & $\begin{array}{c}t- \\
\text { statistic }\end{array}$ & p-value \\
\hline Constant & 49.47 & 7.65 & 6.47 & $<.001$ \\
\hline $\begin{array}{l}\text { GPA in IT2A } \\
\text { to IT2C } \\
\text { lecture-based } \\
\text { classes }\end{array}$ & -.713 & 2.61 & -.27 & 0.785 \\
\hline IT Lab 2 GPA & 7.247 & 2.55 & 2.84 & $0.005^{*}$ \\
\hline Rater \#1 & -18.27 & 4.22 & -0.19 & $<0.001^{*}$ \\
\hline Rater \#2 & 12.14 & 5.80 & 4.29 & 0.039* \\
\hline Rater \#3 & -1.23 & 5.04 & 2.59 & 0.807 \\
\hline Rater \#4 & -12.33 & 5.31 & .76 & $0.022 *$ \\
\hline Rater \#5 & -10.42 & 5.40 & 1.05 & 0.057 \\
\hline Rater \#6 & -14.86 & 5.30 & .37 & $0.006 *$ \\
\hline Rater \#7 & 0.88 & 4.10 & 3.31 & 0.830 \\
\hline Rater \#8 & 1.82 & 4.20 & 3.43 & 0.667 \\
\hline Rater \#9 & 7.76 & 6.02 & 3.57 & 0.200 \\
\hline Rater \#10 & 0.243 & 3.91 & 3.28 & 0.951 \\
\hline Rater \#11 & -19.49 & 5.54 & -0.34 & $0.001 *$ \\
\hline Rater \#12 & -10.54 & 4.98 & 1.09 & $0.037^{*}$ \\
\hline Rater \#13 & 1.71 & 5.45 & 2.91 & 0.755 \\
\hline Rater \#14 & 2.70 & 5.83 & 3.26 & 0.644 \\
\hline Rater \#15 & 2.20 & 5.83 & 2.90 & 0.706 \\
\hline Rater \#16 & 10.55 & 5.92 & 2.83 & 0.078 \\
\hline Rater \#17 & -17.24 & 5.29 & 4.01 & $0.002 *$ \\
\hline
\end{tabular}

Model $\mathrm{R}^{2}=0.510$

Abbreviations: GPA: Grade Point Average; IT: Integrated Therapeutics; OSCE: Objective Structured Clinical Examination;

Some studies showed that an ideal OSCE should be configured in such a way as to minimise any examiner or standardised patient variability (Corbo et al., 2006; Bartman et al., 2013; Sobh et al., 2017). However, another study (Binh et al., 2018) revealed that interrater variability has been seen in OSCEs, and another (Tamblyn et al., 1991) described sources of unreliability and bias in the ratings of standardised patient scenarios.

One study reviewed a pass/fail decision for borderline performers during a summative OSCE and evaluated the reliability between multiple assessors (Ali et al., 2019). They decided that the assessor's decision making was poor by virtue of them having different expectations of performance for the students on each of the competencies (Ali et al., 2019). Another study utilised an OSCE to evaluate performance in postgraduate year one and year two residents (Cauthon et al., 2017). They stated that evaluation of baseline performance is crucial in highlighting a resident's needs in order to tailor their learning experiences (Cauthon et al., 2017). They also utilised trained SPs to grade the 
interaction based on a rubric created by the task force to ensure consistency (Cauthon et al., 2017). The authors' past experience in the College of Pharmacy showed quite the opposite based on the limited expertise of SPs. This was mostly seen in case scenarios where the pharmacist/physician interactions were more difficult for SPs to accurately portray and subsequently grade the therapeutic portion of assessments. The portrayal of SPs as healthcare providers in these situations was not deemed to meet the desired standards, so the activity was designated as a practice/teaching activity.

Reinforcement of training of examiners, SPs, and creation of quality assessments are key to minimising inter-variability in grading. All of the stations roleplayed by SPs must be monitored during the exam to ensure they are role-playing correctly in order to reduce inter-rater variability (Curtis et al., 2019). Nevertheless, a comparison of faculty and SP intervariability grading was conducted in real-time, revealing that when adequately trained, the SPs were equally excellent in grading when compared to the faculty graders in both the communications and therapeutics portion of the OSCE (Stowe \& Gardner, 2005). Like Howard University College of Pharmacy, some healthcare programmes have utilised SPs to grade the OSCEs (Stowe \& Gardner, 2005; Kilminster et al., 2007; Curtis et al., 2019). However, they are often trained to create consistency of grading (Stowe \& Gardner, 2005; Kilminster et al., 2007; Curtis et al., 2019). This process can be beneficial to minimise perceived faculty bias in the grading process. Grading conducted by SPs in our college of pharmacy has been limited to the global assessment scale, which primarily assesses communication skills. This switch from faculty grading to SP grading on the global assessment scale was adjusted in autumn 2019 based on student feedback. Students commented on the possibility of faculty's perceived bias on OSCE grading and expressed concern regarding inconsistencies regardless of a standardised grading rubric. The authors also recognised that there are some barriers to implementing the grading of the therapeutic content of the OSCE by SPs due to the complexity of the cases as well as the perceived diminishing authenticity by students.

Based on the results of the study, the Howard University College of Pharmacy made adjustments to address the aforementioned inconsistencies noted in the faculty grading. One of the changes implemented included having two different faculty review and grade the OSCE, with the student receiving the average of the grades. The other change was having all grading faculty receive the case prior to grading the OSCE in real-time. This process made it easier for the faculty instructors since they had similar expectations and familiarity with the case content, rather than just using a standardised rubric. Additionally, in July 2020, the Howard University College of Pharmacy faculty received additional training on best practices of how to create and grade an OSCE from the Director of the University Clinical Skills and Simulation Center. This training was based on accreditation standards set by simulation bodies such as the American College of Surgeons. The Director also encouraged the incorporation and involvement of subject matter experts throughout the process from case development to implementation of the OSCE. The authors hope to consistently implement these measures to reduce perceived and actual bias from a student standpoint. Future studies would be needed to evaluate the implemented recommendations for sustained feasibility.

\section{Limitations}

There are some limitations to this study, such as this data was only collected for one semester of the curriculum rather than for the entire academic year, which would give the opportunity to see how the student fared across the board and their overall performance. The information collected was only limited to about four classes, including three lecture courses and one laboratory course with a relatively small sample size which could have had a confounding effect on a student's overall performance. Some students could have performed less favourably in the lecture course while doing relatively well in the laboratory-based course, so it is harder to find an association between the two courses.

\section{Conclusion}

Objective Structure Clinical Examinations remain a widely used assessment method in assessing clinical competency. This study found differences in grading among faculty evaluators. It is imperative that training mechanisms are instituted to ensure all evaluators, both faculty and SPs, are equipped to provide consistent, reliable and objective grading when reviewing OSCEs so students are appropriately and fairly evaluated.

\section{References}

Ali, M, Pawluk, S.A., Rainkie, D.C., \& Wilby, K,J. (2019) PassFail decisions for borderline performers after a summative objective structured clinical examination. American Journal 
of Pharmacy Education, 83(2), Article 6849. https://doi.org/10.5688/ajpe6849

Barman, A. (2005) Critiques on the objective structured clinical examination. Annals - Academic Medicine of Singapore, 34(8), 478-482

Bartman, I., Smee, S., \& Roy, M. (2013). A method for identifying extreme OSCE examiners. The clinical teacher, 10 (1), 27-31. https://doi.org/10.1111/j.1743498X.2012.00607.x

Binh, P.D., An, P.L., Tuan, T.D., \& Leppink, J.(2018). InterRater reliability of a professionalism OSCE developed in family medicine training University of Medicine and Pharmacy. MedPharmRes, 2(1), 20-24.

https://doi.org/10.32895/UMP.MPR.2.1.20

Brannick, M.T., Erol-Korkmaz, H.T., \& Prewett, M. (2011). A systematic review of the reliability of objective structured clinical examination scores. Medical Education, 45(12), 1181-1189. https://doi.org/10.1111/j.13652923.2011.04075.x

Cauthon, K.A., Attridge, R.L., Urteaga, E.M., Witte, A.P. (2017) An Objective Structured Clinical Examination to Assess Pharmacy Resident Performance. Innovations in Pharmacy, 8(2), Article 5.

https://doi.org/10.24926/IIP.V812.510

Corbo, M., Patel, J.P., Abdel Tawab R, Davies JG. (2006). Evaluating clinical skills of undergraduate pharmacy students using objective structured clinical examinations (OSCEs). Pharmacy Education. 6, 53-58.

https://doi.org/10.1080/15602210500528372

Curtis, S., Smith, K.J., \& Taylor, J. (2019) Implementation of objective structured clinical examinations (OSCE) in a doctor of pharmacy program. Currents in Pharmacy Teaching and Learning, 11, 832-837.

https://doi.org/10.1016/j.cptl.2019.04.011

Duanmu, Y, Henwood, P.C., Takhar, S.S., Chan, W., Rempell, J.S., Liteplo, A.S., Koskenoja, V., Noble, V.E., \& Kimberly, H.H. (2019). Correlation of OSCE performance and point-ofcare ultrasound scans numbers among a cohort of emergency medicine residents. The ultrasound Journal, 11(1):3. https://doi.org/10.1186/s13089-019-0118-7

Kilminster, S., Roberts, T., Morris, P. (2007). Incorporating patients' assessment into objective structured clinical examinations. Education for Health, 20(6)

Kirton, S.B., \& Kravitz, L. (2011). Objective Structured Clinical Examinations (OSCEs) Compared With Traditional Assessment Methods. American Journal of Pharmacy Education, 75(6), Article 111. https://doi.org/10.5688/ajpe756111

Mafinejad, M.K., Rastegarpanah, M, Moosavi, F, Shirazi, M. (2017). Training and Validation of Standardized Patients for Assessing Communication and Counseling Skills of Pharmacy Students: A Pilot Study. Journal of Research in Pharmacy Practice, 6(2), 83-88. https://doi.org/10.4103/jrpp.JRPP_17_20

Reid, K, Smallwood, D, Collins, M, Sutherland, R, Dodds, A. (2016). Taking OSCE examiner training on the road: reaching the masses. Medical Education Online, 21. https://doi.org/10.3402/meo.v21.32389

Salinitri, F.D., O'Connell, M.B., Garwood, C.L., Lehr, V.T., \& Abdallah, K. (2012). An objective structured clinical examination to assess problem-based learning. American Journal of Pharmacy Education, 76(3), 44. https://doi.org/10.5688/ajpe76344

Shahzad, A., Saeed, M.H.B., Paiker, S. (2017). Dental students' concerns regarding OSPE and OSCE: a qualitative feedback for process improvement. BDJ Open. 9, 3, 17009. https://doi.org/10.1038/bdjopen.2017.9

Shirwaikar, A. Objective structured clinical examination (OSCE) in pharmacy education - a trend. (2015). Pharmacy Practice, 13(4), 627.

https://doi.org/10.18549/PharmPract.2015.04.627

Sobh, A.H., Austin, Z, Izham, M.I.M., Diab, M.I., Wilby, K.J. (2017). Application of a Systematic Approach to Evaluating Psychometric Properties of a Cumulative Exit-From-Degree Objective Structured Clinical Examination (OSCE). Currents in Pharmacy Teaching and Learning, 9(6), 1091-1098. https://doi.org/10.1016/j.cptl.2017.07.011

Solà, M., Pulpón, A.M., Morin, V., Sancho, R., Clèries, X., Fabrellas, N. (2017). Towards the implementation of OSCE in undergraduate nursing curriculum: A qualitative study. Nurse Education Today. 49, 163-167. https://doi.org/10.1016/j.nedt.2016.11.028. 7

Stowe, C.D., \& Gardner, S.F. (2005). Real-Time Standardized Participant Grading of an Objective Structured Clinical Examination. American Journal of Pharmacy Education, 69(3) Article 41. https://doi.org/10.5688/aj690341

Sturpe, D.A. (2010). Objective structured clinical examinations in the doctor of pharmacy programs in the United states. American Journal of Pharmacy Education, 74(8) Article 148. https://doi.org/10.5688/aj7408148

Tamblyn, R.M., Klass, D.J., Schnabl, G.K., \& Kopelow, M.L. (1991). Sources of unreliability and bias in standardizedpatient rating, Teaching and Learning in Medicine, 3(2), 7485. https://doi.org/10.1080/10401339109539486

Vanka, A., Wali, O., Akondi, B.R., Vanka, S., Ravindran, S. (2018). OSCE: A New Assessment Method for Pharmaceutical Education. Indian Journal of Pharmaceutical Education and Research, 52(4s), S1-s6. https://doi.org/10.5530/ijper.52.4s.68 